This PDF is a selection from an out-of-print volume from the National Bureau of Economic Research

Volume Title: An Appraisal of the 1950 Census Income Data

Volume Author/Editor: Conference on Research in Income and Wealth

Volume Publisher: Princeton University Press

Volume ISBN: 0-691-04102-4

Volume URL: http://www.nber.org/books/unkn58-2

Publication Date: 1958

Chapter Title: The Survey of Consumer Finances and the Census Quality Check

Chapter Author: Monroe G. Sirken, E. Scott Maynes, John A. Frechtling

Chapter URL: http://www.nber.org/chapters/c1051

Chapter pages in book: (p. 123 - 166) 


\section{PART II}

The Matching and Quality Check Studies 


\title{
The Survey of Consumer Finances and the Census Quality Check
}

\author{
Monroe G. Sirken, Department of health, \\ EDUCATION, AND WELFARE
}

E. Scott Maynes, university of MinNesota

JOHN A. FrechtLING, FORD MOTOR COMPANY

\section{Introduction}

Persistent differences have often been detected in income figures collected in independently conducted household field surveys of about the same population groups. This has been true even when the estimates of the income size distributions were found to be fairly similar. As a recent and striking example of such a difference, proportionately fewer people are usually shown in the upper-income brackets of estimates based on surveys conducted by the Bureau of the Census than on those conducted regularly by the Survey Research Center (SRC) of the University of Michigan for the Board of Governors of the Federal Reserve System (FRB) as the Survey of Consumer Finances (SCF).

Previous comparisons of field surveys have suggested various reasons for the differences found between the resulting income size distributions. But it has been almost impossible to pin down the

Note: At the time the present study was conducted, Mr. Sirken was a member of the staff of the Bureau of the Census; Mr. Maynes, of the Survey Research Center of the University of Michigan; Mr. Frechtling, of the Board of Governors of the Federal Reserve System.

There are many persons in the Survey Research Center, the Bureau of the Census, and the Federal Reserve Board who participated in one phase or another of this study. The authors wish to acknowledge especially the assistance of George Katona, John B. Lansing, Charles Cannell, Leslie Kish, and James N. Morgan of the Survey Research Center; Morris Hansen, William N. Hurwitz, Eli S. Marks, and Leon Pritzker of the Bureau of the Census; and Ralph Young, Homer Jones, and Irving Schweiger of the Federal Reserve Board. Also the authors wish to acknowledge that the analytical work in this report was assisted by a contract with the Office of Naval Research.

Although this report represents the joint effort of the three authors, the major responsibilities for writing the report were divided among them. Mr. Sirken wrote the "Introduction" and "General Differences in Execution"; Mr. Frechtling, "Reporting of Major Components of Income." Mr. Maynes wrote "Improvement of Survey Techniques and of the Interpretation of Survey Data" and also contributed to the "Summary and Conclusions" at the end of each of the two previous sections. 
cause and effect relationships because the survey income data being studied were not originally collected with their future comparison in mind. During 1950, the Bureau of the Census, the SRC, and the FRB undertook a joint income study to provide data for this purpose. The plan of the study involved a resurvey by the Bureau of the Census of a subsample of dwelling units contained in the 1950 SCF. In the resurvey, called here the Census Quality Check (CQC), the Bureau used the enumerators and questionnaires it had used in the Post-Enumeration Survey (PES), which was the quality check undertaken to evaluate the completeness and reliability of the 1950 census. Personal income reports for 1949 were collected in both the original survey and the resurvey.

Thus the present paper can offer an analysis of differences between the income reports collected by two survey organizations using an identical sample design. Its authors hope that the discussion of the reasons that were found for the differences between the reports will provide information useful to others-to the survey technician in improving the field survey as a technique for collecting personal income reports, to the income analyst in evaluating data collected in this way, and to the statistician in suggesting what processes cause random and bias errors in the reports of income collected by household surveys.

\section{THE STUDY PLAN AND ITS IMPLEMENTATION}

During January and February of 1950, the SCF collected reports of their 1949 annual money income from persons in a national probability sample of dwelling units. The sample consisted of lists of dwelling units in urban areas and of open-country segments in rural areas. ${ }^{1}$ The basic sampling rate was about one in 16,500 dwelling units, and about 3,000 families and unrelated persons were interviewed. High-income families and farmers, however, were oversampled. If occupants of urban dwelling units were believed to have annual incomes of at least $\$ 6,000$, the units were sampled at six times the basic rate; if between $\$ 3,000$ and $\$ 6,000$, at twice the basic rate. Rural farm dwelling units were also sampled at twice the basic rate.

In August and September of 1950, about seven months after the original enumeration by the SCF, the Bureau of the Census conducted a resurvey (CQC) of a random selection of the SCF dwelling units. The CQC enumerators covered about one-half of the addresses in the urban list sample and dwelling units in one-half

${ }^{1}$ A segment is a small area with defined boundaries within which interviews are taken at all dwelling units. 
of the open-country segments in each of the sixty-six primary sampling areas in the SCF sample.

The SCF and CQC enumerators had almost the same information to identify the sample dwelling units. In urban areas, enumerators were supplied with the addresses of the sample units and also of the immediately preceding and succeeding units. In rural areas, they were given highway maps or aerial photographs showing the boundaries of the segments.

Persons covered by each survey were assembled into income units of families and unrelated persons. These were weighted so that all had the same probability of selection. Thus, income units in dwelling units sampled at the regular rate in the SCF were counted six times; those in dwellings sampled at twice the regular weight, three times; and those in dwellings sampled at six times the regular weight, only once.

Since the persons covered in the SCF were not identified by name, the demographic characteristics of families and heads of families covered by each survey at the same listed address or within the same rural segment were compared. If the characteristics of the two units were sufficiently similar (according to specified rules), they were taken as the same or "matched" units; if not, as different or "unmatched" units. ${ }^{2}$ Almost all the matched units were assigned the same sampling weight in both surveys, although occasionally a matched unit in an open-country segment had different weights in the SCF and in the CQC. ${ }^{3}$

\section{INTERPRETATION OF THE DATA}

To be able to interpret correctly the data obtained in the surveys, various qualifying factors must be taken into account. In addition to limitations resulting from the sample and the study design, two other important qualifying factors and their possible effects on the data will be considered here.

\section{The Period between the Surveys}

The long period between the enumeration dates in the SCF and in the $\mathrm{CQC}$ probably detracted somewhat from a primary objective of the study, which was to conduct both surveys under essentially the same conditions. In the SCF, persons were asked about their 1949 income about one or two months after the end of the calendar year and about one month before the final date for filing 1949 income tax returns; in the $\mathrm{CQC}$, the enumeration period was about

\footnotetext{
${ }^{2}$ See Appendix $\mathrm{A}$ for a description of the matching procedure.

${ }^{3}$ For an explanation of how this happened, see page 136.
} 
eight or nine months after the end of 1949 or about six months after the final filing date.

What effect the factor of memory had on the size of income reported was not determined in the study. But one likely effect of the long period between the two enumerations was to decrease the correlation between the size of income reported in one and in the other.

The length of the period also affected the matching of units. Since about 20 per cent of the families in the nation moved during 1950 , about 12 per cent of the units covered in the SCF could be expected to have moved by the CQC date. The CQC enumerators tried to track down nearby migrants. But under the optimistic assumption that they were successful in finding all within-county migrants, about 8 per cent of the units covered in the SCF would have been missed by the CQC enumerators because they had moved outside the county. Sometimes the $\mathrm{CQC}$ enumerators could reconstruct the household composition for units that had migrated too far to be found, and so the CQC units could be matched with the SCF units; sometimes they could not, and so the SCF unit was not matched. Either way, the CQC income of the units was not likely to have been ascertained. Doubtless there were also cases in which the $\mathrm{CQC}$ enumerators did not detect that the SCF unit had moved, and so the CQC incomes are for different units from the ones the SCF had found at the sample address.

\section{The Lack of Names}

The fact that the SCF did not record the names of persons covered increased the chances for making two types of error in matching the SCF and $\mathrm{CQC}$ units: (1) different units were erroneously classified as matched units, and (2) the same units were erroneously classified as unmatched units. In view of the rigid matching rules applied, there were probably more matching errors of the second type than of the first. If so, the percentage of units reported as matched represents an undercount of the actual percentage. Matching errors of the first kind would probably reduce the correlation between income reports of matched units in the two surveys.

In view of the limitations of the survey design and its implementation, the data were not inflated to the national level, and sampling errors were not computed. However the data are weighted to a common sampling level to adjust for the oversampling of higherincome households and farmers in the design of the 1950 SCF. Thus the weighted sample sizes referred to in this report are on the average about four times greater than the actual sample sizes. 


\section{COMPARISON OF THE TOTAL INCOME REPORTS}

All families and unrelated persons covered either in the SCF or CQC, appropriately weighted, are cross-tabulated by total income in Table 1. Unmatched units not covered in the CQC are distributed in line 12 by the total income reported in the SCF, and those not covered in the SCF are distributed in column 12 by the total income reported in the CQC. The matched units are tabulated in the other lines and columns.

Units selected at different sampling rates are distributed in line 11 according to income reported in the SCF and in column 11 according to income reported in the CQC. Matched units sampled at the same rate in both surveys for which total income was not ascertained in the $\mathrm{CQC}$ are distributed in line 10 according to the income reported in the SCF and those for which total income was not ascertained in the SCF are distributed in column 10 according to the total income reported in the CQC. Matched units sampled at the same rate and reporting income in both surveys are cross-tabulated in lines 1 to 9 and columns 1 to 9 according to the total income reported in both surveys.

The marginal frequencies in lines 1 to 10 and columns 1 to 10 respectively of Table 1 represent the distributions of CQC and SCF families and unrelated persons by total income size. Percentage distributions based on these frequencies (see Table 2, p. 144) are rather similar for the two surveys, but the distribution of income derived from $\mathrm{CQC}$ reports is more heavily weighted at the lower income levels. The median income is about $\$ 115$ greater in the SCF than in the CQC.

The frequencies in the cells on the main diagonal of lines and columns 1 to 9 in Table 1 represent units which reported income in the same income class to both surveys; the frequencies in all other cells represent units that reported income in different classes. What are the main factors that produced the differences in the reported incomes? How do they operate? And what effect does each factor have on the differences between the two surveys in the percentage distribution by income size? Can findings here be applied generally to the collection of personal income by household surveys? These are the principle questions considered in this report.

\section{General Differences in Execution}

The reasons for differences between the SCF and $\mathrm{CQC}$ total income size distributions discussed in this section will be those relating to 


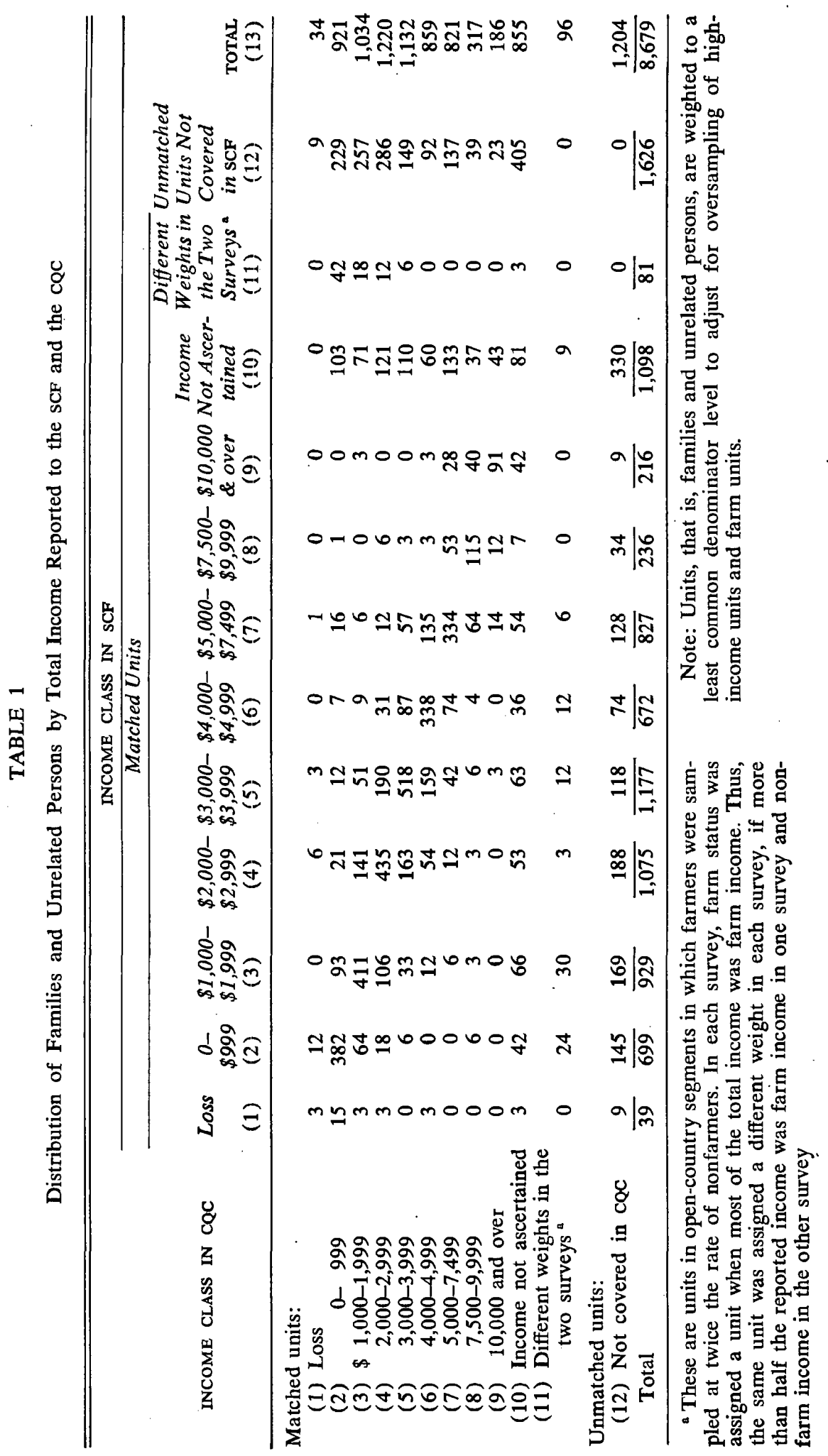


six differences in the way the two field surveys carried out the sample design. The accompanying tabulation shows what the six differences were and their relative importance.

\begin{tabular}{|c|c|c|}
\hline Survey Differences & $\begin{array}{r}\text { Units } \\
\text { in Botl } \\
\text { (number) }\end{array}$ & $\begin{array}{l}\text { vered } \\
\text { urveys } \\
\text { (per cent) }\end{array}$ \\
\hline $\begin{array}{l}\text { Total units }{ }^{\mathrm{A}} \\
\text { Unmatched }\end{array}$ & $\begin{array}{r}8,679 \\
-2,830 \\
5,849\end{array}$ & $\begin{array}{r}100.0 \\
32.6\end{array}$ \\
\hline Differently weighted & $\begin{array}{r}-\quad 177 \\
5,672\end{array}$ & 2.0 \\
\hline No income report in one or both & $\frac{-1,125}{4,547}$ & 12.9 \\
\hline Differed in number of adults & $\begin{array}{r}-250 \\
4,297\end{array}$ & 2.9 \\
\hline Differed in number of income recipients & $\begin{array}{r}-987 \\
3,310\end{array}$ & 11.4 \\
\hline Not first quality respondent in one or both & $\begin{array}{r}-898 \\
2,412\end{array}$ & 10.3 \\
\hline $\begin{array}{l}\text { Units affected by survey differences } \\
\text { Units unaffected by survey differences }\end{array}$ & $\begin{array}{l}6,186 \\
2,412^{b}\end{array}$ & $\begin{array}{l}72.1 \\
27.9\end{array}$ \\
\hline
\end{tabular}

The effect of each difference will be determined by analysis of the income size distributions of the SCF and CQC units representing the source of difference. Thus the effect of differences in the coverage of units will be studied by an analysis of the income size distributions of the unmatched SCF and $\mathrm{CQC}$ units. The effect of other differences will be analyzed successively in the order listed above. The units covered in the analysis of each reason for difference will be eliminated from the subsequent analysis. Consequently, on completion of the analyses contained in this section of the report, the only units not eliminated are those unaffected by the differences between the SCF and CQC considered here, that is, matched units, selected at the same rate in both surveys, for which total income was ascertained in both, and in which the same adults were covered, the same income recipients were reported, and best-quality respondents were interviewed in both.

DIFFERENCES IN COVERAGE, IN SAMPLING RATE, AND IN NONRESPONSE RATE

\section{Unmatched Units}

A weighted total of 8,598 families and unrelated persons (actual sample size, 2,201) was covered by the SCF and CQC. ${ }^{4}$ Of these,

"Assuming that the matched units sampled at different rates in the two surveys are given the SCF weights. 


\section{MATCHING AND QUAIITY STUDIES}

2,827 , or about one-third, were not matched. (This should not be interpreted as one-third of the United States population, since nonmatches could be counted as two separate units, but matched units as only one.) The total unmatched units consist of 1,204 SCF units not matched with $\mathrm{CQC}$ units and 1,626 CQC units not matched with SQF units. The surplus of CQC units represents about 5 per cent of the units covered in both surveys or about 15 per cent of the unmatched units.

It is not surprising that more units were covered in the CQC than in the SCF. A major CQC objective was to evaluate the coverage of population in the 1950 census, as it had been for the PES, and the enumerators were specifically trained and the questionnaires designed with this goal in mind. Consequently, in the resurvey, a separate coverage questionnaire was completed for each dwelling unit and several pages of questions were included to ensure that sample dwelling units were listed and resident persons were enumerated. There was no equivalent to this coverage questionnaire and coverage questions in the SCF. In the tabulation unmatched income units are distributed by population size of the city of residence.

\begin{tabular}{|c|c|c|c|c|c|}
\hline \multirow[b]{2}{*}{ CITY SIZE } & \multirow{2}{*}{$\begin{array}{l}\text { TOTAL } \\
\text { UNITS }\end{array}$} & \multicolumn{2}{|c|}{$\begin{array}{l}\text { UNMATCHED UNITS } \\
\text { Covered in: }\end{array}$} & \multirow{2}{*}{$\begin{array}{c}\text { PERCENTAGE } \\
\text { Un- } \\
\text { matched }\end{array}$} & \multirow{2}{*}{$\begin{array}{l}\text { OF UNITS } \\
\text { CQC } \\
\text { Surplus }\end{array}$} \\
\hline & & SCF & CQC & & \\
\hline Total & 8,598 & 1,204 & 1,626 & 32.9 & 4.9 \\
\hline Metropolitan areas & 2,329 & 247 & 323 & 24.5 & 3.3 \\
\hline 50,000 and over & 1,452 & 175 & 329 & 34.7 & 10.6 \\
\hline $2,500-50,000$ & 1,852 & 208 & 282 & 26.4 & 4.0 \\
\hline Under 2,500 & 1,376 & 263 & 275 & 39.1 & 0.9 \\
\hline Open-country areas & 1,589 & 311 & 417 & 45.7 & 6.7 \\
\hline
\end{tabular}

- Urban, suburban, and rural areas surrounding the twelve largest cities in the United States.

Errors in identifying the sample dwelling units probably contributed substantially to the number of unmatched income units. In general, there is a negative correlation between the percentage of unmatched income units and city size. For example, the percentage of unmatched units is about 25 per cent in metropolitan areas and about 46 per cent in open-country areas, where the proportion of unmatched units is about one and a half times greater than in all places where individual sample dwelling units were prelisted. ${ }^{5}$

More income units were always covered in the $\mathrm{CQC}$ than in the SCF, but there is no apparent correlation between the percentage surplus of CQC units and city size. Thus the excess of $\mathrm{CQC}$ units represents about 7 per cent and 11 per cent of the units covered

${ }^{5}$ The technical problem of matching is more difficult for units in open-country segments. For these one must match not only all the income units at a particular address but also all the dwelling units in a particular segment (about four to eight per segment on the average in this study). 
by both surveys in open-country areas and in cities of 50,000 or more, respectively, and ranges between 1 and 4 per cent elsewhere.

In some cases unmatched units were apparently missed in one of the surveys. Many of these units were located in cities of 50,000 and over, which largely explains why this city size has so high a proportion of unmatched units and so large an excess of CQC units. The evidence that the units were missed is that in each case one survey (1) covered more families and unrelated persons in a dwelling unit in which one or more other family units were matched, or (2) detected more occupied dwelling units in a multiple-dwellingunit structure in which family units in other dwelling units in the same building were matched, or (3) covered family units in a well identified dwelling unit reported vacant in the other survey. Almost all the 368 income units identified as presumably missed were located in urban areas and were missed in the SCF. They account for nearly all the excess of units covered by $\mathrm{CQC}$ in nonrural areas. The table shows the unmatched income units distributed by size of total income reported in each survey.

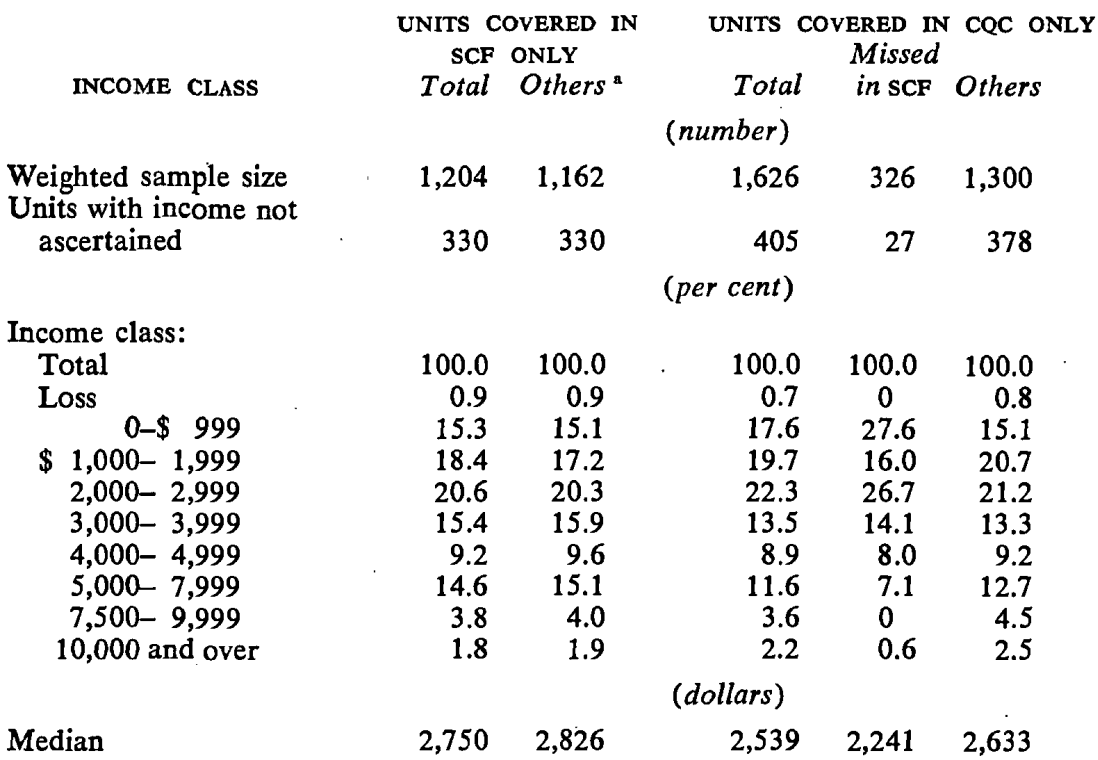

- There were only 42 units in the weighted sample that were presumably missed in the CQC though covered in the SCF, too few to compute a percentage distribution.

In each survey, the unmatched units are lower-income units, on the average, than the matched units (see Table 2, below). Thus, the median income of matched units is greater than the median income of unmatched units by about $\$ 500$ in the SCF and by about $\$ 675$ in the CQC. Also, as might be expected, there is closer agree- 
ment between the surveys in the income distributions of matched units than of unmatched units. For example, the median income of the matched units is almost the same in both surveys, but the median income of the unmatched units is over $\$ 200$ greater in the SCF than in the CQC.

Why is the median income greater for units covered in the SCF only than for units covered in the CQC only? The income distribution of units presumably missed in the SCF provides a clue. These units report less income, on the average, than other unmatched units. That is, the SCF tends to miss a group comprising about 5 per cent of the population whose average income is lower than that of the population as a whole.

\section{Units Sampled at Different Rates}

Income units in which farm income comprised at least one-half the total income were oversampled in the SCF. This was accomplished in the following manner. In the SCF, open-country segments were selected at twice the basic sampling rate; in one half all income units were counted, in the other half only farm income units were counted. ${ }^{6}$ To compensate, the income reports of farm units were weighted three times and the income reports of nonfarm units, six times. As a result, a matched unit in a farm segment reporting farm income as over half of total income in one survey and as less than half in the other survey did not have the same weighting in both.

The SCF method of oversampling farm units increased somewhat the divergence between the SCF and $\mathrm{CQC}$ distributions of total income. Based on the actual weights assigned in each survey, the median income of these units is $\$ 854$ greater in the SCF than in the CQC. If the units had been sampled at the SCF rate in both surveys, the SCF median would have been $\$ 765$ higher, if at the CQC rate in both, only $\$ 223$ higher.

\section{Units with Income Not Ascertained}

Income was not ascertained for a higher proportion of matched units in the SCF ( 16 per cent) than in the CQC (11 per cent). CQC

${ }^{\circ}$ The procedures for selecting the farm units in open-country segments were somewhat different in the SCF and in the CQC. The SCF enumerators asked a few questions to find out which were farm units, not recording the answers, and then asked the farm income questions only of the farm units. In the CQC, all units were interviewed using the same questionnaire, and the farm units were identified when the schedules were edited. The unmatched CQC nonfarm units in open-country segments were excluded entirely from the study. The matched CQC nonfarm units in these segments were used in some of the following analyses but were assigned a weight of zero in the CQC income distributions. 
units in open-country segments were matched with 1950 census enumerations, and, if there was no $\mathrm{CQC}$ income report but there was a census income report, it was substituted. However, this use of census reports probably did not materially increase the $\mathrm{CQC}$ income response rate.

Reports on total income are missing in either or in both surveys for a weighted total of 1,125 matched units sampled uniformly in both surveys, representing about 69 per cent (SCF) and 53 per cent (CQC) of all units without income reports. Of the 1,125 units, 678 had only a CQC report, 366 only a SCF report, and 81 had no report in either. In the accompanying table, units without total income reports in one survey are distributed by the total income reported in the other. These distributions show a higher percentage of units in the upper-income classes, particularly in the $\$ 10,000$-and-over class, than distributions of units for which total income was ascertained in both surveys. The median income of units with total income reported only to the CQC is about $\$ 100$ higher than that of units with total income reported only to the SCF, although the $\$ 10,000$-and-over class in the SCF is proportionately about twice the size of the same class in the CQC.

\begin{tabular}{|c|c|c|c|c|}
\hline INCOME CLASS & \multicolumn{2}{|c|}{$\begin{array}{c}\text { UNITS WITH ONLY } \\
\text { SCF INCOME } \\
\text { Partial CQC }\end{array}$} & $\begin{array}{l}\text { UNITS } \\
\text { CQC }\end{array}$ & $\begin{array}{l}\text { WITH ONLY } \\
\text { INCOME } \\
\text { SCF Non- } \\
\text { interview }\end{array}$ \\
\hline & \multicolumn{4}{|c|}{ (number) } \\
\hline Weighted sample size & \multicolumn{4}{|c|}{ (per cent) } \\
\hline \multicolumn{5}{|l|}{ Income class: } \\
\hline Total & 100.0 & 100.0 & 100.0 & 100.0 \\
\hline Loss & 0.8 & 1.0 & 0 & 0 \\
\hline $0-\$ 999$ & 11.5 & 12.8 & 15.2 & 16.0 \\
\hline$\$ 1,000-1,999$ & 18.0 & 19.7 & 10.5 & 10.4 \\
\hline $2,000-2,999$ & 14.5 & 17.4 & 17.8 & 15.5 \\
\hline $3,000-3,999$ & 17.2 & 15.7 & 16.2 & 17.1 \\
\hline $4,000-4,999$ & 9.8 & 9.8 & 8.8 & 9.0 \\
\hline $5,000-7,499$ & 14.8 & 9.5 & 19.6 & 19.7 \\
\hline $7,500-9,999$ & 1.9 & 0.3 & 5.5 & 5.9 \\
\hline 10,000 and over & 11.5 & 13.8 & 6.3 & 6.2 \\
\hline & \multicolumn{4}{|c|}{ (dollars) } \\
\hline Median & 3,302 & 2,948 & 3,400 & 3,474 \\
\hline
\end{tabular}

a The sample size of noninterviews in the $\operatorname{coc}(61)$ is too small to compute a percentage distribution.

b The sample size of partial interviews in the SCF (54) is too small to compute a percentage distribution.

SCF noninterviews - the income informant was missed or refused to answer-account for about 92 per cent of the matched units 
without SCF total income reports. Partial interviews-the interview was begun but total income was not recorded-accounted for about 83 per cent of the missing income reports in the CQC. The distributions show that while the noninterviewed represented a higherincome group on the whole, a higher proportion of the partially interviewed were in the $\$ 10,000$-and-over class. Apparently the $\mathrm{CQC}$ enumerators were more successful in initiating interviews, but the SCF enumerators were more successful in obtaining the income for the unit once the interview had been initiated.

DIFFERENCES IN COVERAGE OF ADULTS, OF INCOME RECIPIENTS, AND IN QUALITY OF RESPONDENT

After eliminating the differing units discussed in the three previous subsections, 4,547 units remain (actual sample size, 1,148). They represent matched families and unrelated persons, sampled at the same rate, for which total income was ascertained in both surveys - the units cross-tabulated by size of total income in columns 1 to 9 and lines 1 to 9 of Table 1 . In the following sections the questions to be answered are whether a higher or lower percentage of units would have reported income in the same class in both surveys and whether the SCF and $\mathrm{CQC}$ income size distributions would have been more similar if all the units had shown the same number of adults and income recipients and if only first quality respondents had been interviewed. The procedure of a step-by-step elimination of units differing in these respects will be used again.

\section{Units Differing in Number of Adults}

Among the 4,547 units, there are 250 families in which a different number of adults (persons eighteen years of age or older) were covered. ${ }^{7}$ In 174 more adults were covered in the cQC, and in 76 , more in the SCF.

Differences in the rules for assigning place of residence in the two surveys do not explain why proportionately more units with more adults were covered in the CQC than in the SCF. With one exception, the rules were almost the same in both surveys. The exception was that to determine the place of residence of college students not enumerated at home, the home address was chosen as the place of residence in the SCF; the college address, in the CQC. But this difference favored the enumeration of larger families in the SCF rather than in the CQC.

A more likely explanation is the greater emphasis given to ques-

'If the SCF and CQC differed on the number of adults in a family, the units were not considered matched unless there was exceptional agreement on other items. 
tions of coverage in the CQC than in the SCF. For example, the CQC enumerator listed the members of the dwelling unit and then asked several questions to make sure that no persons had been missed; for example, they asked whether there were any persons away traveling or visiting friends or relatives. The SCF enumerators also listed the members of the dwelling unit, but they did not ask specifically about who might have been missed.

The median income of the 250 families in which a different number of adults was covered in the two surveys is $\$ 3,772$ in the SCF, $\$ 4,622$ in the CQC. About two-thirds (67.6 per cent) did not report total income in the same income class in both surveys. About 42 per cent reported income in a higher class in the CQC than in the SCF; the corresponding percentage for the SCF is 21.6. For all the units, about 25 per cent reported income one class higher in one survey or the other, 42 per cent one or more classes higher, and 17 per cent two or more classes higher.

There is strong evidence that the adults covered in one survey but missed in the other had substantial incomes. Among units in which more adults were covered in the SCF, about 68 per cent reported income in a higher bracket in the SCF and none reported income in a higher bracket in the CQC. The corresponding percentages for the CQC are 60.4 and 6.8. Moreover, of these units, about 32 per cent reported income more than one bracket higher in the SCF and about 40 per cent more than one bracket higher in the CQC.

The matched families in which a different number of adults were covered in the two surveys are shown in the accompanying distribution according to their total incomes. The median CQC income is

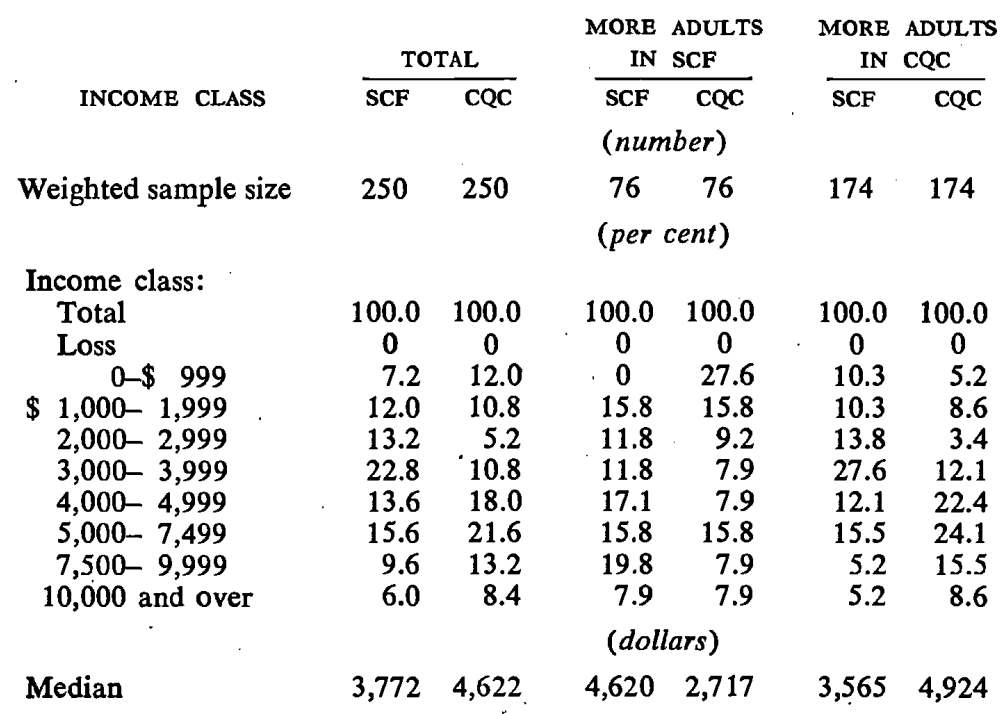


$\$ 1,359$ greater than the median SCF income for families in which CQC shows more adults; the median SCF income is $\$ 1,903$ greater than the median CQC income for families in which the SCF shows more adults. But since there are more than twice as many units in which more adults are shown in the CQC than units with more adults in the SCF, the CQC median income of all units in which the number of adults differ is $\$ 1,050$ higher than the SCF median for the same units.

\section{Units Differing in Number of Income Recipients}

After the elimination of families in which a different number of adults were covered in the two surveys, 4,297 matched units are left. In 987 of these the surveys differ on the number of income recipients in the unit, although the identical persons seem to have been included in both surveys in almost all of the units. Consequently the difference in the number of income recipients represents a reporting rather than a coverage difference between the surveys.

Of the 987 units, more than twice as many show more income recipients in the CQC (689) than in the SCF. (298). The difference between the interviewing units used in the two surveys may help to explain the greater number of income recipients in the CQC. The basic interviewing unit in the SCF was the spending unit, comprising adults and their dependents in a family receiving $\$ 10$ per week or more income who pooled their incomes. On the other hand, the individual was the basic unit in the CQC. This difference in the basic unit is reflected in the difference in the type of questionnaire used; a separate questionnaire was completed for each spending unit in the SCF and for each member of the family in the CQC. It seems reasonable to suppose that the $\mathrm{CQC}$ interviewing procedure would be likely to detect more income recipients, particularly secondary income recipients, than the SCF procedure.

About 43.5 per cent of the units differing in the number of income recipients shown reported income in a different income class in the two surveys, but the proportion of units reporting more income was about the same in both-about 21.4 per cent in the SCF and 21.9 per cent in the CQC. However, the median income of all 987 units is $\$ 3,246$ (SCF income) or $\$ 3,374$ (CQC income).

Unlike the missing adults, persons covered in both surveys but reporting income in only one apparently did not have large incomes. Consequently almost two-thirds of the units with more income recipients either in the SCF or in the CQC reported income in the same income bracket in both surveys. Relatively few reported income more than one income class higher in one survey than in the other. 


\section{S C F A N D C Q C}

Of the units with more income recipients in the SCF, 23 and 15 per cent, respectively, reported income one bracket, and more than one bracket, higher in the SCF; and about 4 and 1 per cent, respectively, in higher brackets in the CQC. The corresponding percentages for the $\mathrm{CQC}$ units with more income recipients are 20 and 10 per cent (higher $\mathrm{CQC}$ income) and about 11 and 4 per cent (higher SCF income).

The matched units in which a different number of income recipients were reported in both surveys are distributed by total income in the accompanying table. The median income of the units in which there are more SCF income recipients is $\$ 829$ higher in the SCF than in the CQC; the median income of the units in which there are more CQC income recipients is $\$ 350$ higher in the CQC than in the SCF. Nevertheless, the median income of all units in which a different number of income recipients were reported is $\$ 128$ higher in the $\mathrm{CQC}$ because more than twice as many units reported more income recipients in the CQC than in the SCF.

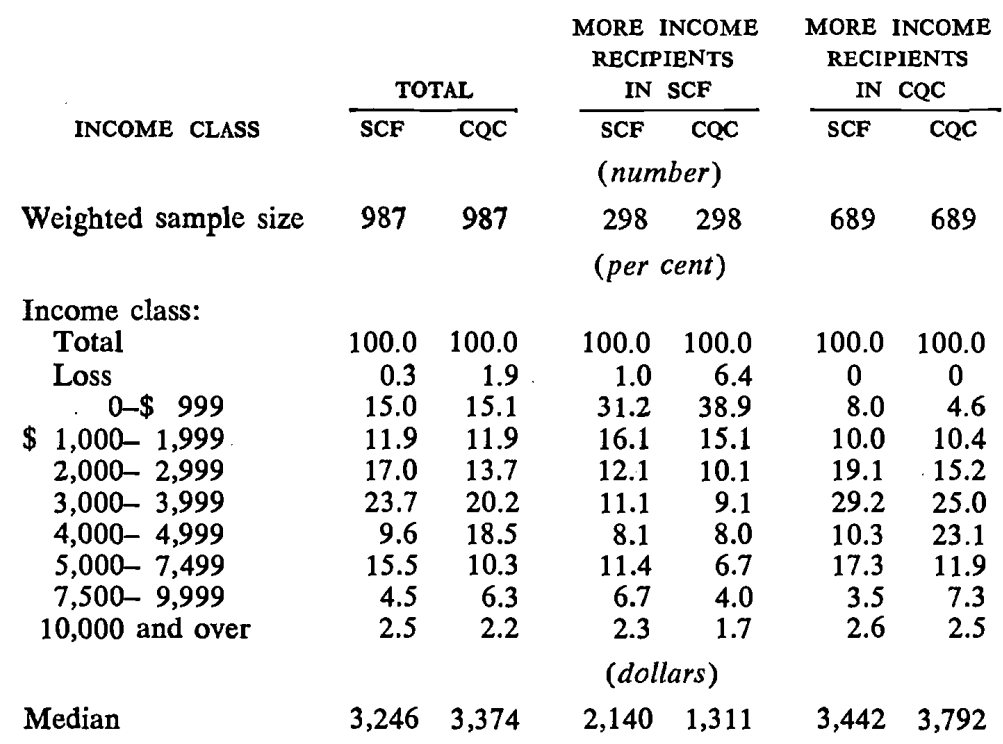

\section{Units in Which First-Quality Respondents Were Not Interviewed}

Of the 3,310 weighted sample units remaining after deducting units that differed in the number of income recipients in the two surveys, best-quality respondents were not interviewed in about 24 per cent of the SCF units and in about 13 per cent of the CQC units. There are 898 units in which the respondents were not first quality 


\section{MATCH ING AND QUALITY STUDIES}

in either one or both surveys, 457 in the SCF, 119 in the CQC, and 322 in neither.

A stricter definition of first-quality respondent was applied in the CQC than in the SCF. Thus a family was considered to have a first-quality respondent in the SCF if the head of the spending unit answered for the whole unit but in the $\mathrm{CQC}$ only if all income recipients answered for themselves. Hence the actual disparity between the surveys in the percentage of units with best-quality respondents may favor the $\mathrm{CQC}$ even more than the figures indicate. The differences between the surveys both in the questionnaires and in the instructions given the enumerators probably account for the higher rate of first-quality correspondents in the CQC than in the SCF (for example, the difference in the basic income unit used noted in the previous subsection).

About 47 per cent of the units in which at least one of the respondents was not first quality reported income in different income brackets in the two surveys, and a net of about 10 per cent reported income in a higher bracket in the SCF. The median income of these units is $\$ 3,379$ in the SCF and $\$ 3,267$ in the CQC, or $\$ 112$ higher in the SCF.

The percentages of units in which first-quality respondents were not interviewed in one or both surveys are shown in the accompanying table according to the survey in which income was reported in a higher bracket. The extent of agreement of income reports appears to be greater for units in which first-quality respondents were not interviewed in both surveys than for units in which they were

\begin{tabular}{|c|c|c|c|c|c|}
\hline INCOME CLASS" & $\begin{array}{l}\text { FIRST-Q } \\
\text { In SCF } \\
\text { Only }\end{array}$ & $\begin{array}{c}\text { LITY RES } \\
\text { In CQC } \\
\text { Only }\end{array}$ & $\begin{array}{c}\text { ONDENT } \\
\text { In } \\
\text { Neither }\end{array}$ & $\begin{array}{c}\text { TOTAL ALL } \\
\text { UNITS WITH } \\
\text { OTHER THAN } \\
\text { FIRST-QUALITY } \\
\text { RESPONDENTS }\end{array}$ & $\begin{array}{l}\text { FIRST-QUALITY } \\
\text { RESPONDENT IN } \\
\text { BOTH SURVEYS }\end{array}$ \\
\hline & \multicolumn{5}{|c|}{ (number) } \\
\hline Weighted sample size & \multicolumn{5}{|c|}{ (per cent) } \\
\hline Total & 100.0 & 100.0 & 100.0 & 100.0 & 100.0 \\
\hline Same class & 53.8 & 48.4 & 60.4 & 53.3 & 62.6 \\
\hline Different class & 46.2 & 51.6 & 39.6 & 46.7 & 37.4 \\
\hline Higher class in SCF & 30.2 & 29.5 & 25.7 & 28.3 & 20.8 \\
\hline One higher & 25.2 & 23.6 & 16.4 & 21.3 & 16.1 \\
\hline More than one higher & 5.0 & 5.9 & 9.3 & 7.0 & 4.7 \\
\hline Higher class in CQC & 16.0 & 22.1 & 13.9 & 18.4 & 16.6 \\
\hline One higher & 13.5 & 19.9 & 10.2 & 15.6 & 13.9 \\
\hline More than one higher & 2.5 & 2.2 & 3.7 & 2.8 & 2.7 \\
\hline Net surplus in SCF & 14.2 & 7.4 & 11.8 & 9.9 & 4.2 \\
\hline
\end{tabular}

- The income classes are those shown in previous tables. 
S G F A N D C Q C

interviewed in only one. Thus about 60 per cent of the units in which first-quality respondents were interviewed in neither reported income in the same bracket in both compared to 54 and 48 per cent, respectively, in which they were interviewed in the SCF only or in the CQC only.

However, as the table indicates, the SCF and CQC income distributions are in closest agreement for units in which first-quality respondents were interviewed in both surveys, although there are still substantial differences-37.4 per cent reported income in a different income bracket in the two surveys and a net surplus of 4.2 per cent reported income in a higher bracket in the SCF than in the CQC. The distribution of the units in which there were not firstquality correspondents is shown in another tabulation according to the SCF and CQC reported income. The agreement is not so close as it is for the units in which first-quality respondents were interviewed in both surveys (see Table 2, below). However the median incomes of the latter are lower. The likely explanation is that a smaller percentage of first-quality respondents are interviewed in high-income than in low-income units.

\begin{tabular}{|c|c|c|}
\hline \multirow[t]{2}{*}{ INCOME } & \multicolumn{2}{|c|}{ 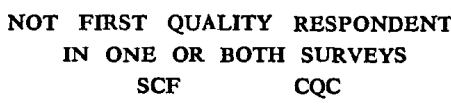 } \\
\hline & \multicolumn{2}{|c|}{ (number) } \\
\hline Weighted sample size & 898 & 898 \\
\hline Income class: & \multicolumn{2}{|c|}{ (per cent) } \\
\hline $\begin{array}{l}\text { Total } \\
\text { Loss } \\
\quad 0-\$ 999 \\
\$ 1,000-1,999 \\
2,000-2,999 \\
3,000-3,999 \\
4,000-4,999 \\
5,000-7,499 \\
7,500-9,999 \\
10,000 \text { and over }\end{array}$ & $\begin{array}{r}100.0 \\
1.3 \\
4.7 \\
12.5 \\
24.1 \\
19.5 \\
16.7 \\
12.4 \\
5.7 \\
3.2\end{array}$ & $\begin{array}{l}100.0 \\
0 \\
6.7 \\
17.5 \\
21.0 \\
18.0 \\
17.5 \\
13.3 \\
3.5 \\
2.6\end{array}$ \\
\hline 10,000 and over & \multicolumn{2}{|c|}{ (dollars) } \\
\hline
\end{tabular}

Median

$3,379 \quad 3,267$

SUMMARY AND CONCLUSIONS

On the basis of the six factors just considered, the CQC did a better job than the SCF did in carrying out the survey in the field. Working from the same list of addresses and open country segments, the $\mathrm{CQC}$ enumerators found more families and unrelated individuals, more adults per family, more income receivers per family, and more first-quality respondents. How did the differences in the 


\section{A T C H I N G A N D Q UALITY ST UDIES}

two surveys affect the income size distributions? Table 2 gives the percentage distributions at three stages-before any units were eliminated, after only the unmatched units were eliminated, and the units that remain at the end of all the eliminations, that is, those unaffected by any of the six differences.

TABLE 2

Effect on SCF and CQC Income Distributions of Elimination of Units for the Six Differences

\begin{tabular}{|c|c|c|c|c|c|c|}
\hline \multirow[b]{2}{*}{ INCOME CLASS } & \multicolumn{2}{|c|}{ All Units } & \multicolumn{2}{|c|}{$\begin{array}{c}\text { After } \\
\text { Eliminating } \\
\text { Unmatched Units }\end{array}$} & \multicolumn{2}{|c|}{$\begin{array}{c}\text { Units } \\
\text { Unaffected } \\
\text { by Differences a }\end{array}$} \\
\hline & SCF & CQC & SCF & CQC & SCF & $\mathrm{CQC}$ \\
\hline & & & \multicolumn{2}{|c|}{ (number) } & & \\
\hline \multicolumn{7}{|l|}{ Weighted sample size: ${ }^{b}$} \\
\hline Total & \multicolumn{2}{|c|}{8,679} & \multicolumn{2}{|c|}{5,849} & \multicolumn{2}{|c|}{2,412} \\
\hline \multirow[t]{2}{*}{ Each survey } & 6,972 & 7,379 & 5,768 & 5,753 & 2,412 & 2,412 \\
\hline & & \multicolumn{5}{|c|}{ (per cent) } \\
\hline \multicolumn{7}{|l|}{ Income class: } \\
\hline Total & .100 .0 & 100.0 & 100.0 & 100.0 & 100.0 & 100.0 \\
\hline Loss & 0.7 & 0.5 & 0.6 & 0.5 & 0.5 & 0.3 \\
\hline $0-\$ 999$ & 11.9 & 14.1 & 11.2 & 13.1 & 11.6 & 12.8 \\
\hline$\$ 1,000-1,999$ & 15.8 & 15.8 & 15.3 & 14.7 & 16.8 & 16.0 \\
\hline $2,000-2,999$ & 18.4 & 18.7 & 17.9 & 17.7. & 17.3 & 19.2 \\
\hline $3,000-3,999$ & 20.0 & 17.4 & 21.0 & 18.4 & 21.5 & 19.9 \\
\hline $4,000-4,999$ & 11.4 & 13.2 & 11.9 & 14.4 & 11.2 & 13.3 \\
\hline $5,000-7,499$ & 14.1 & 12.6 & 14.0 & 12.9 & 13.9 & 11.4 \\
\hline $7,500-9,999$ & 4.0 & 4.9 & 4.1 & 5.2 & 3.2 & 4.8 \\
\hline 10,000 and over & 3.7 & 2.8 & 4.1 & 3.0 & 4.0 & 2.3 \\
\hline \multirow{3}{*}{$\begin{array}{l}\text { Percentage reporting in } \\
\text { come in same class }\end{array}$} & \multirow{2}{*}{\multicolumn{2}{|c|}{30}} & \multirow{2}{*}{\multicolumn{2}{|c|}{45}} & \multirow{2}{*}{\multicolumn{2}{|c|}{63}} \\
\hline & & & & & & \\
\hline & & & \multicolumn{2}{|c|}{ (dollars) } & & \\
\hline Median & 3,162 & 3,047 & 3,238 & 3,214 & 3,177 & 3,085 \\
\hline Excess of SCF over CQC & \multicolumn{2}{|c|}{115} & \multicolumn{2}{|c|}{24} & \multicolumn{2}{|c|}{92} \\
\hline
\end{tabular}

" That is, matched units, sampled at the same rate, in which both surveys had reports on total income, identified the same adults and income receivers, and interviewed first-quality respondents.

'The units are weighted to a least common denominator level to adjust for over-sampling of high-income and farm units. The actual sample size of all units is 2,$201 ; 1,804$ in the SCF and 1,928 in the CQC. The remainder, the units unaffected by the differences, is actually 619 units. In the first two sets of distributions the units for which income was not ascertained are distributed proportionately.

On the average, the $\mathrm{CQC}$ found 5 per cent more families and unrelated individuals than the SCF did. The excess of CQC units was greatest for large, but not metropolitan, areas (11 per cent) and open-country areas ( 7 per cent), and least for towns under 2,500 and metropolitan areas. Since units in the areas where the $\mathrm{CQC}$ ex- 


\section{S C F A N D C Q C}

cess was greatest tended to have lower incomes than the average for all areas, this excess lowered the $\mathrm{CQC}$ income distribution relative to the SCF one.

Nonmatched units constitute 17 per cent of all units covered by the SCF, 22 per cent of all those covered by the CQC. Nonmatches are units covered in one survey for which almost identical units could not be found in the other survey under the matching rules, though some of the units were actually covered in both surveys. Families or individuals had moved and could not be found (probably 60 per cent of the SCF units, 45 per cent of the CQC units). Or they were living in the same place but were not interviewed in one of the surveys because they were not at home (SCF, about one-third; CQC, about one-quarter), or were missed (the CQC missed fewer). Or the composition of the families had changed substantially between the two survey dates, or the unit was inaccurately described in one of the surveys. (Particular units cannot be assigned to these categories.) The median income of the unmatched units is relatively low in both surveys, $\$ 2,750$ for the SCF and $\$ 2,539$ for the CQC.

The SCF and $\mathrm{CQC}$ distributions of families and unrelated persons are in closer agreement after eliminating unmatched units from the distributions, and at a generally higher level of income (Table 2). The percentage reporting incomes in the same class rises from 30 to 45 per cent and the median incomes are only $\$ 24$ apart instead of $\$ 115 .^{8}$ Thereafter the elimination of units in open-country segments that were not sampled at the same rate and of matched units for which income was not ascertained in either or both surveys have a relatively small effect on the difference in the median income between the two surveys.

Among the matched units, the $\mathrm{CQC}$ was more successful than the SCF in obtaining complete income reports. Refusals to answer, respondents not at home or ill, language barriers, and so forth, account for not obtaining such reports in 11 per cent of the $\mathrm{CQC}$ units, in 16 per cent of the SCF units. Reports were obtained in the SCF for 53 per cent of the $\mathrm{CQC}$ units that lacked them; the median income of these units is $\$ 3,302$, of which 11.5 per cent reported incomes of $\$ 10,000$ or more. Similarly, for 69 per cent of the SCF units lacking reports, the $\mathrm{CQC}$ obtained them; the median income is $\$ 3,400$. Only 6.3 per cent of these CQC units reported incomes $\$ 10$,000 and over, proportionately about half as many as in the SCF group.

\footnotetext{
${ }^{8}$ The classes referred to throughout this summary are those shown in Table 2 and elsewhere in this section.
} 


\section{MATCHING AND QUALITY STUDIES}

Apparently the income distributions would have been in closer agreement if the same units had been covered and sampled at the same rate in the two surveys. But they would have been in greater disagreement if income had been ascertained for all units in both surveys. A result of eliminating units for the three differences is to raise the median income in both (from $\$ 3,162$ to $\$ 3,264$ in the SCF and from $\$ 3,047$ to $\$ 3,245$ in the CQC).

The two surveys differed in the number of adults shown in a unit in about 3 to 4 per cent of the units remaining after the elimination of those affected by the first three factors. There is evidence that the adults missed had substantial incomes. The number of units differing in the number of income recipients is higher, about 13 to 14 per cent in both surveys. In this factor as in the other coverage factors, the CQC was more successful than the SCF. In 70 per cent of these units the $\mathrm{CQC}$ found more recipients, the SCF found more in only 30 per cent. Because it found more, the level of the CQC distribution was affected more than that of the SCF one. Units where the $\mathrm{CQC}$ reported a larger number have a higher median income $(\$ 3,800)$ than units where the SCF found a larger number $(\$ 2,140)$. However, supplementary income recipients uncovered by the SCF tended to add more income to the total received by the unit than did those uncovered by the CQC.

In 27 to 28 per cent of the units in both surveys (matched, and with the same number of adults and income recipients) first-quality respondents were not interviewed. Again the CQC was more successful than the SCF, accounting for 51 per cent of this group compared to 13 per cent for the SCF. In 36 per cent of cases neither survey interviewed first-quality respondents.

The percentage of persons reporting income in the same class in both surveys changes with the elimination of the various divergent units. Starting with 30 per cent for all the units covered in both surveys, eliminating the unmatched units raises this to 45 per cent. It falls to 42.8 per cent when units sampled at different rates are removed, rises to 57.2 per cent with the removal of units without reports on total income, and to $59.2,60.1$, and 62.6 per cent with the successive elimination of units differing in the number of adults, and income recipients, and lacking first-quality respondents. But while the elimination of the first three groups raises the median income in both surveys, the elimination of the last three lowers them in both. This is to be expected, since obviously in family units having several adults the chances are greater that differing numbers of adults or income recipients will be reported or that second-quality respondents will be interviewed than in single person units, so 
a higher proportion of the latter will be left. And single persons tend to have lower incomes than families.

If other factors had been constant, the evidence is that if the same number of adults had been covered in both surveys, the same number of income recipients had reported income, and all income recipients had reported for themselves in both surveys, the SCF and CQC income distributions would probably have been in greater disagreement than they are. But a larger percentage of the units would probably have reported total income in the same income class in both surveys.

All in all, the extent of agreement of the income size distributions in the two surveys was virtually unaffected by the differences arising from the six factors discussed so far. Both before and after eliminating the differing units the distribution based on the SCF reports shows a higher percentage in the upper-income classes than that based on the CQC reports, and a median income about $\$ 100$ greater. This lack of change came about because better performance by the CQC than by the SCF did not consistently result in larger CQC income reports. The excess of units covered in the $\mathrm{CQC}$ and apparently missed in the SCF were below-average-income units. On the other hand, better performance by the CQC on the other criteria discussed resulted in larger income reports in the CQC than in the SCF for the same units, though not enough to remove the bias in the distributions shown by the difference in the medians.

Matched units with identical adults, income recipients, and firstquality respondents constituted about one third of all the CQC and SCF units; a weighted sample of 2,412 units, 619 actual units. Of this select group, 63 per cent reported total income in the same income class in both surveys, 93 per cent in the same or adjacent income classes. The next section of this paper is devoted to an analysis of how the two surveys compared in the reports of major sources of income by these units.

\section{Reporting of Major Components of Income}

The examination of how differences between the two surveys in their questionnaires and interviewing situations affected their income reports will be based on the 619 actual units (weighted sample size 2,412 ) which were matched, sampled at the same rate in both surveys, and in which the same adults and income receivers were identified and first-quality respondents interviewed. ${ }^{9}$ The vari-

${ }^{\circ}$ The SCF questionnaire is given in Appendix B of this paper, the CQC questionnaire, which was the one used in the PES, on page 237 of this volume. 
ous forms of income pose widely differing reporting problems, and each will be considered in turn.

The elimination of various categories of unmatched and partially matched units reduced the weighted number of units to 33 per cent of the total CQC units and 35 per cent of the SCF total. As previously indicated, this group cannot be regarded as a random slice of the population. The inconclusive results of our examination of entrepreneurial incomes underlines again the need for the experiments on income reporting by farmers and businessmen. But we believe that for wages and salaries and the various minor sources of income, our 619 cases proved a large enough group to yield fairly firm conclusions on the direction, if not on the precise magnitude, of reporting differences.

\section{THE INTERVIEWING SITUATION}

The "total interviewing situation" is a slippery subject, involving possibilities rather than firm conclusions. The most concrete difference between the surveys is that the SCF interview took place about one and one-half months, the $\mathrm{CQC}$ interview about nine months, after the close of the year for which income was being obtained. If people do tend to forget small items more readily than large ones, minor sources of income should be reported more fully in the SCF than in the CQC. This apparently was the case.

Also the attitudes of both interviewers and interviewed may be assumed as different in surveys conducted by private research organizations and governmental agencies. The private interviewers may have to work harder to establish rapport and thus obtain a more complete account of income; the governmental interviewers may receive more cooperation from the interviewed. We can only point out these possibilities. But they indicate the desirability of using the same interviewing corps both times in similar experiments.

All groups should proceed with such projects. For while general principles of questionnaire design may be established, differences in the relationship to respondents such as those encountered by the Bureau of the Census and the Survey Research Center may make modifications desirable. And although much pretesting of questionnaires has already been done, few results have been systematically reported to users of income distribution data.

\section{NUMBER OF COMPONENTS REPORTED}

If wages and salaries, self-employment income, and all other forms of income taken together are considered as the three major 


\section{S C F A N D C Q C}

income components, an average of 1.42 components was reported to the CQC and of 1.47 to the SCF by the 619 units. Wages and salaries accounted for almost all of the difference, as 76 per cent reported such income to the SCF and only 72 per cent to the CQC (Table 3 ). The amount of income reported by the additional recipient units tended to be small, so that the median wages and salary income is smaller for the group in the SCF than in the CQC. However for the 70 per cent reporting wages and salaries to both, the amounts reported tended to be larger in the SCF.

It is hard to interpret these results because the CQC asked each income recipient for a detailed job history, but the SCF asked each spending unit only three rather general questions. Possibly the dulling of recall by the passage of an extra seven months more than offset the presumed superiority of the more detailed questionnaire. Or the SCF question on work outside of regular employment may have been more effective than the CQC question on part-time work and odd jobs because the SCF question was one of three, while the single CQC question followed an extended series used to complete the job history. Furthermore, the CQC question appeared overleaf from the job history, and the interviewer had to turn the page to enter any part-time or odd jobs.

Although the discrepancies between the results of the two surveys for wages and salaries are puzzling, they are relatively small compared to the differences for other kinds of income. And the large proportion who reported wages and salaries in the same or adjoining income brackets (66 per cent) or who reported zero wages and salaries to both surveys indicates the stability of the data. Whether asking for a job history rather than for answers to a few questions is a more valid method or yields enough additional income data to be worth the cost is a question that should receive attention in the near future. The length of the period for which income is to be obtained is especially relevant in this connection.

\section{SELF-EMPLOYMENT INCOME}

Self-employment income accounted for only a minor part of the net additional major income sources reported to the SCF. This result is not unexpected since a comparatively small proportion of the population are self-employed.

Reports to only one survey, or, if to both, discrepancies of more than one income class in the amount reported, were much more frequent for self-employment income than for wages and salaries. While 9.0 per cent of the units reported self-employment income in the same class in both surveys, 8.5 per cent reported such income 
TABLE 3

Distribution of Similar Families and Unrelated Persons by Major Component of Income Reported to the SCF and CQC

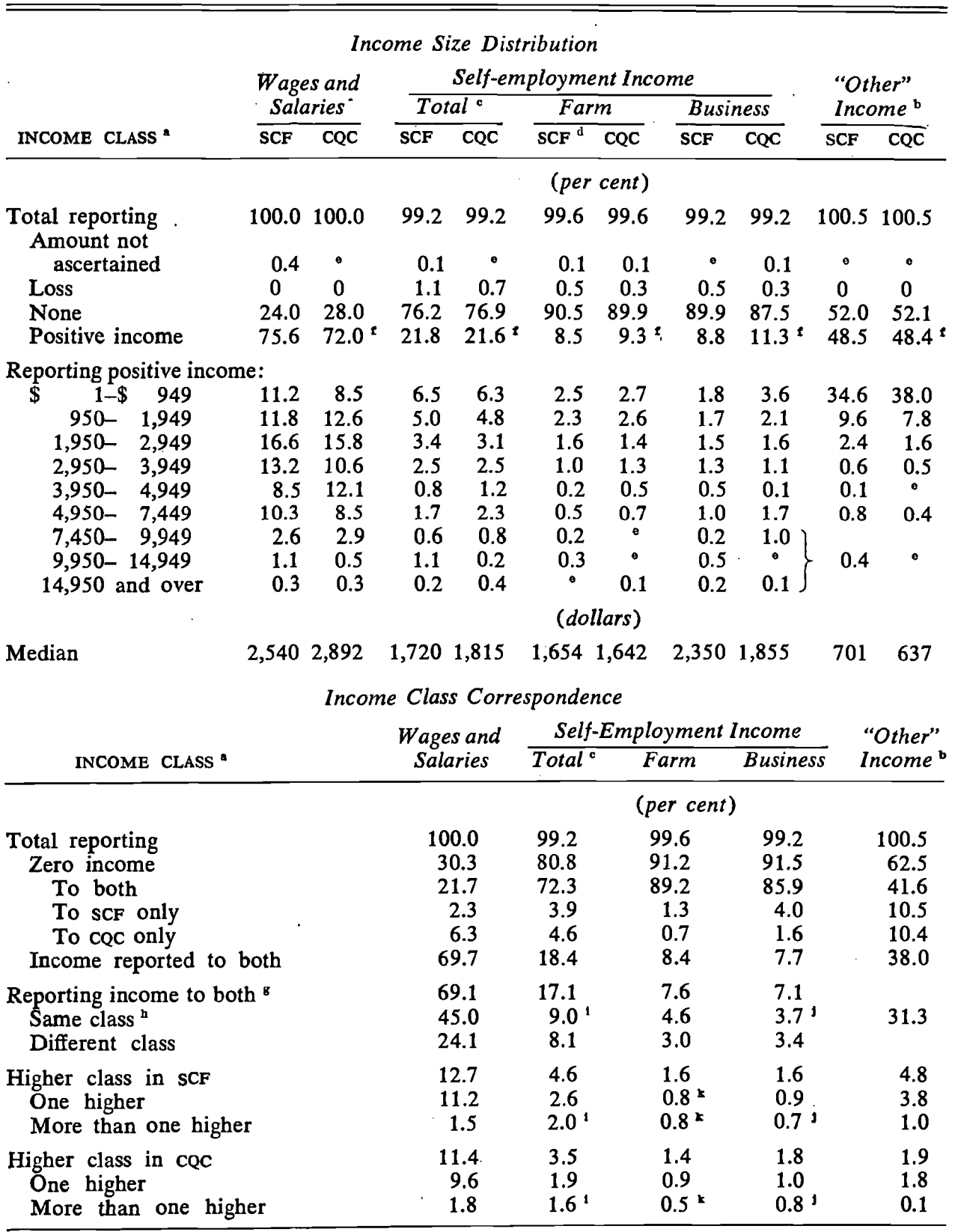

a The income classes refer to the amount of each type of income reported, not to total income.

notes continued on next page 


\section{S C F A N D C Q C}

\section{Notes to TABLE 3, continued}

b "Other" income includes rental, dividend and royalty, interest, and transfer payment income, and all additional forms of income other than wages and salaries and self-employment income.

' Includes farm, business, professional, and similar self-employment income.

'Of farm operators only.

- No cases reported or less than 0.05 per cent.

' This figure includes units whose income was reported as " $\$ 10,000$ and over," and therefore they cannot be distributed between the two highest classes shown below. These units constituted 0.2 per cent of those reporting wages and salaries, 0.1 per cent of those reporting "other" income, and either less than 0.05 per cent or none of those reporting income in the other categories.

"Excludes units in which the amount was not ascertained and the cQc " $\$ 10,000$ and over" class.

${ }^{\mathrm{h}}$ Based on the income classes shown in this table.

' Positive incomes only. In addition, 0.3 per cent reported negative incomes to both, 0.1 per cent negative incomes to the $\mathrm{CQC}$ and zero to the SCF, 0.3 per cent negative incomes to the $\mathrm{CQC}$ and positive to the $\mathrm{SCF}$, and 0.8 per cent reported negative incomes to the SCF and positive incomes to the $\mathrm{CQC}$.

' Positive incomes only. In addition, 0.2 per cent reported negative incomes to both, 0.1 per cent negative incomes to the $\mathrm{CQC}$ and zero to the SCF, 0.1 per cent negative income to the SCF and zero to the CQC, and 0.3 per cent negative incomes to the SCF and positive incomes to the CQC.

${ }^{k}$ Positive incomes only. In addition, the 0.5 per cent reporting losses to the SCF and the 0.3 per cent reporting losses to the CQC reported positive incomes to the other survey in all cases.

to only one survey and 3.6 per cent reported income differing by more than one class. Yet the difference in median self-employment income between the two surveys is only $\$ 95$. An examination of farm and nonfarm self-employment income separately reveals both conceptual and procedural differences between the surveys.

\section{Farm Income}

The SCF used two sets of farm income questions. If farm income was a minor source of income, the interviewer asked one question on net income; if a major source, an extended series of questions on cash expenses and cash receipts. (However, the list of expenses was not exhaustive; one obvious omission was property taxes.) In contrast, the $\mathrm{CQC}$ interviewer asked only for gross income and for income net of farm expenses but asked this of all units with farm income.

Secondly, the SCF procedure of an extended series of questions seemed better able to prevent certain types of capital expenditures from appearing as expenses than the CQC one. Expenditures on machinery, buildings, and so forth, were obtained specifically in a section devoted to savings. A conceptual difference between the surveys was that the SCF assigned the value of increases in livestock and in privately financed crop inventories to expenses, but the $\mathrm{CQC}$. asked that they be excluded from expenses, although it did not provide an explicit check. 


\section{MATCHING AND QUALITY STUDIES}

The comparison of the farm income data from the two surveys is inconclusive because so few units were involved. The slight excess of units reporting farm incomes to the CQC in part reflects the SCF coding procedure, in which farm income obtained as a secondary source was not coded with farm income obtained from the extended series of questions. Comparison of the distributions indicates that the SCF one tends to be somewhat flatter. However the medians of the two distributions are quite close, a result consistent with the conceptual difference noted, since net income may be expected to vary less widely than net cash flow which excluded changes in inventories.

\section{Nonfarm Income}

For nonfarm self-employment income, the CQC obtained gross and net receipts by using the same questions described above for farm income, plus a question to find out whether the net income reported included "salary" and other cash withdrawals. If not, these were determined and added to net income.

The SCF used several questions to obtain nonfarm self-employment income. It distinguished between unincorporated business income and professional and other self-employment income which represents payment primarily for the work of persons, with capital playing a minor role. Owners of unincorporated business were asked for their net profit (or loss) and their withdrawals in the income section, and were also asked about the liquidation of all or part of a business in the savings schedule.

A priori, the SCF schedule seems superior to the CQC one on two counts. First, it picks up explicitly income from investments in unincorporated businesses that do not involve the self-employment of the investor. Such income would presumably be reported in answer to the clean-up question at the end of the CQC schedule, but it is not explicitly mentioned in the interview. Secondly, the SCF question on liquidation may have prevented some liquidation from being treated as income. However, it is an open question whether some respondents know enough about accounting to answer accurately this question or many others designed to elicit income as defined by economists.

The net incomes of professional persons and of others of the self-employed not classed as business owners were obtained by a single SCF question, which also obtained any incidental self-employment income, such as payments for work done in home workshops.

As in the case of the two kinds of farm income, the SCF did not combine the incomes of business owners with those of professional 
persons and others self-employed, so there is no complete, separate SCF coding of nonfarm self-employment income. Again the excess of units reporting such income to the CQC (Table 3 ) probably reflects this omission. The CQC median is lower than that of the SCF because the omitted SCF self-employment income presumably was dominated by part-time self-employment.

And again like the farm income, the data on nonfarm self-employment income are based on too small a sample to furnish anything except leads for further investigation. For this type of income alone the SCF reported incomes tended to run lower than the CQC incomes for the same units, reflecting perhaps the SCF questions on the net income estimate and a consequent elimination of liquidation proceeds from income.

\section{Total Self-Employment Income}

The distributions of total self-employment incomes include the SCF secondary farm incomes and nonfarm, nonbusiness self-employment incomes coded separately by the SCF. Probably as a result, the excess of $\mathrm{CQC}$ reports disappears. With the inclusion of these usually secondary incomes in the SCF distribution, the SCF median income $(\$ 1,720)$ falls below the CQC median $(\$ 1,815)$. The proportion of units reporting self-employment income to only one survey is as high as the proportion for wages and salaries even though the latter form of income is much more common.

Units reporting self-employment income to both surveys tended to report higher amounts to the SCF than to the $\mathrm{CQC}$, in spite of the slight tendency for the SCF farm incomes to be higher and the SCF nonfarm business incomes to be lower than their CQC counterparts. The cause may be the addition of the income reports of the selfemployed professional persons and other self-employed, who may have given gross rather than net incomes in answer to the one question on net income. And the many checks provided by the other financial questions may also have produced higher reports by this group in the SCF.

\section{"OTHER" INCOME}

The findings on "other" income are more in line with received dogma. For the sum of four minor types of income-rents; interest, dividends, and royalties; proceeds from roomers and boarders; and public and private transfers-the SCF median (\$701) was higher than the CQC one (\$637). In each survey the percentage of units reporting other income to it alone is more than one-fifth of the total reporting other income. For units reporting such income in different 
classes in the two surveys, the SCF clearly obtained larger amounts.

Turning to the components of other income (Table 4), we find that the CQC obtained more and generally higher reported income from transfer payments, but the reverse was true for the other three components. These results were to be expected in view of the questionnaire design. The $\mathrm{CQC}$ devoted six questions to public and private transfer income; the SCF, only two. Similar questions were used in both surveys to obtain interest and other forms of property income, but the SCF also asked questions on ownership and on the value of the related assets in other sections of the questionnaire. This could be expected to improve the reporting of income.

In contrast to the distributions of income from major sources, in these distributions the survey with more units reporting income also had a higher median. This indicates that the extra incomes picked up were not much smaller than the incomes reported to both surveys, although of course all incomes of this sort are marginal for most income recipients.

Despite the indications that a better questionnaire design can improve the reporting of this type of income, the proportion reporting income to only one survey is uncomfortably large. For example, 12 per cent reported interest, dividend, or royalty income to the SCF, but another 4 per cent reported such income to the CQC only. This indicates that these minor forms of income are substantially understated by the surveys.

\section{SUMMARY AND CONCLUSIONS}

Only about one-third of the SCF and CQC units (619) were involved in the comparison of income reporting in the two surveys. These were the matched units, sampled at the same rate, which had identical adults and income recipients and for which there were income reports based on the replies of first quality respondents.

The SCF was more successful than the CQC in obtaining reports of major sources of income; the average number of sources reported to the SCF was 1.47 , to the CQC, 1.42. More frequent reports of wages and salaries in the SCF account for most of the difference -76 per cent for the SCF, 72 per cent for the CQC. Among those reporting wage and salary income to both surveys, reports of $\$ 7,450$ or more occurred with equal frequency. However reports of wages and salaries of $\$ 9,950$ or more were made almost half again as frequently to the SCF as to the CQC. The 6 per cent of the units that reported wage and salary income to the SCF but zero income to the CQC (the corresponding percentage for units reporting said income to the $\mathrm{CQC}$ but none to the SCF was 2) reported relatively small amounts of income on the average. 
TABLE 4

Distribution of Similar Families and Unrelated Persons by Component of "Other" Income Reported to the SCF and CQC

\begin{tabular}{|c|c|c|c|c|c|c|c|c|}
\hline \multirow[b]{3}{*}{ INCOME CLASS } & \multicolumn{8}{|c|}{ Income Size Distribution } \\
\hline & \multicolumn{2}{|c|}{$\begin{array}{c}\text { Income From } \\
\text { Roomers and } \\
\text { Boarders }\end{array}$} & \multicolumn{2}{|c|}{$\begin{array}{c}\text { Rent From } \\
\text { Property }\end{array}$} & \multicolumn{2}{|c|}{$\begin{array}{c}\text { Interest, } \\
\text { Dividends, } \\
\text { and Royalties }\end{array}$} & \multicolumn{2}{|c|}{$\begin{array}{c}\text { All Other } \\
\text { Types }\end{array}$} \\
\hline & SCF & $\mathrm{CQC}$ & $\overline{\text { SCF }}$ & $\mathrm{CQC}$ & SCF & CQC & SCF & $\mathrm{CQC}$ \\
\hline & \multicolumn{8}{|c|}{ (per cent) } \\
\hline Total reporting & 99.8 & 99.8 & 99.6 & 99.6 & 99.8 & 99.8 & 99.6 & 99.6 \\
\hline Amount not ascertained & 0.1 & c & 0.1 & c & 0.3 & ${ }^{\circ}$ & 0.2 & c \\
\hline None & 96.0 & 97.5 & 88.3 & 90.8 & 87.7 & 91.5 & 67.6 & 65.7 \\
\hline Positive income & 3.7 & 2.3 & 11.2 & 8.8 & 11.8 & 8.3 & 31.8 & 33.9 \\
\hline \multicolumn{9}{|l|}{ Reporting positive income: } \\
\hline$\$ \quad 1-\$ 99$ & 0.5 & 0.3 & 0.1 & 0.6 & 4.7 & 4.0 & 3.4 & 2.7 \\
\hline $100-499$ & 2.7 & 1.3 & 5.9 & 6.2 & 3.7 & 2.1 & 14.2 & 16.5 \\
\hline $500-\quad 999$ & 0.2 & 0.6 & 2.1 & 1.0 & 1.7 & 0.9 & 9.0 & 8.8 \\
\hline $1,000-1,999$ & 0.1 & 0.1 & 1.2 & 0.4 & 1.2 & 1.0 & 4.9 & 5.4 \\
\hline $2,000-2,999$ & 0 & 0 & 1.1 & 0.4 & 0.3 & 0.3 & 0.2 & 0.5 \\
\hline $3,000-4,999$ & 0.2 & c & 0.5 & $c$ & 0.2 & 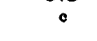 & 0.1 & $c$ \\
\hline \multirow[t]{2}{*}{5,000 and over } & 0 & 0 & 0.3 & 0.2 & 0 & 0 & 0 & 0 \\
\hline & \multicolumn{8}{|c|}{ (dollars) } \\
\hline Median & a & a & 500 & 345 & 240 & 185 & 450 & 488 \\
\hline
\end{tabular}

Income Class Correspondence

Income from Roomers and

INCOME CLASS
Boarders

Rent from

Property
Interest,

Dividends, All Other and Royalties Types"

\begin{tabular}{lrrrr} 
Total reporting & 99.8 & 99.6 & 99.8 & 99.6 \\
$\quad \begin{array}{l}\text { Zero income } \\
\text { To both }\end{array}$ & 94.8 & 85.4 & 83.6 & 60.9 \\
To sCF only & 1.2 & 2.9 & 4.1 & 6.7 \\
To CQC only & 2.7 & 5.4 & 7.9 & 4.8 \\
Income reported to both & 1.1 & 5.9 & 4.2 & 27.2 \\
Reporting income to both & 1.1 & 5.8 & 4.2 & 27.0 \\
Same class & 0.9 & 4.0 & 2.9 & 19.9 \\
Different class & 0.2 & 1.8 & 1.3 & 7.1 \\
Higher class in scF & 0.2 & 1.6 & 0.8 & 2.5 \\
One higher & 0.2 & 1.1 & 0.6 & 2.2 \\
More than one higher & $\mathrm{b}$ & 0.5 & 0.2 & 0.3 \\
Higher class in cQC & & 0.2 & 0.5 & 4.6 \\
One higher & - & 0.1 & 0.4 & 3.7 \\
More than one higher & $\mathrm{c}$ & 0.1 & 0.1 & 0.9 \\
\hline
\end{tabular}

a The income classes refer to the amount of each type of income reported, not to total income.

b Includes social security benefits, alimony, veterans pensions, and other forms of public and private transfer payments.

" No cases reported or less than 0.05 per cent.

'Too few cases for computation.

excludes units in which the amount of income was not ascertained.

${ }^{t}$ Based on income classes shown in this table. 
The SCF-CQC differences in reports of farm and nonfarm selfemployment income were larger in size than for any other type of income. Of those units reporting such income to both surveys 20 per cent reported amounts differing by more than one income class; ${ }^{10}$ the comparable figure for wage and salary income is 5 per cent. Though the median self-employment income reported to the CQC $(\$ 1,815)$ was close to the SCF median $(\$ 1,720)$, twice as many units reported self-employment income of $\$ 9,950$ or more to the SCF than to the $\mathrm{CQC}$.

"Other" income-all income except wages, salaries, or self-employment income-was reported by 21 per cent of the units to one survey but not to the other. This 21 per cent was evenly divided between the two surveys. The units that reported such income to both surveys reported larger amounts to the SCF one and one-half times as often as to the CQC. Transfer payments alone, however, were reported a little more often to the CQC than to the SCF ( 34 versus 32 per cent). And when they were reported to both, a higher amount was reported almost twice as often to the $\mathrm{CQC}$ as to the SCF.

This examination of the reporting of types of income underscores the dependence of results on the techniques and definitions employed. More work is needed, especially on the reporting of entrepreneurial incomes where new techniques may be in order, unlike the reporting of wages, salaries, and the other nonbusiness, nonfarm incomes, where improvements involve more careful application of known principles. Since for some purposes the return from such efforts may not be worth the cost of the improvements, a clearer specification than any now available of the problems toward whose solution the data are to be used is necessary before a conclusion can be reached. A desire for improvement should not blind us to the usefulness at times of the short questionnaire, which yields quicker if less accurate results than a detailed schedule.

\section{Improvement of Survey Techniques and of the Interpretation of Survey Data}

If an original purpose of the research described here is to be fulfilled, what we have learned must be used in the improvement of techniques by survey technicians and of interpretation of survey data by income analysts. The detailed findings have already been summarized. In brief, the CQC enumerators, working from the same list of addresses and open-country segments, found more families

${ }^{10}$ The income classes referred to are those shown in Table 3. 
and unrelated individuals, more adults and income receivers per family, and more first-quality respondents than the SCF enumerators did. On the other hand, for the units unaffected by these differences, the SCF interviewers obtained reports of more sources of income and-for most types of income-a higher mean or median income. Both results are consistent with the known emphasis placed by the Census Bureau on enumeration and by the SCF on financial information.

\section{THE PROBLEM OF VALIDITY}

Interpretation of the results confronts us with the problem of validity; we do not have "true" figures with which to compare them. ${ }^{11}$ Lacking a valid benchmark, each individual will have to judge for himself what kinds of findings are most valid.

As to coverage, most people think that the more properly identified units, adults, or income receivers there are in a category, the more valid the result. They argue that an interviewer is more likely to find too few than to find too many. He may easily miss a janitor's quarters in an apartment house or an apartment above a garage; miss an adult, especially if enumeration is a small part of his activities; or miss an income receiver, especially if the income is small and a long interview appears necessary. He is less likely to make mistakes in the other direction and include in the sample too many families, adults, or income receivers because he has counted a dwelling unit as 1312 Main Street when in fact it is 1313 Main Street or counted as a member of the family an adult who resides elsewhere most of the time. Still, the common belief that the higher the number of unit, adults, and so forth, the more valid the result, is an assumption, not a tested conclusion.

Similarly, most people think that the higher the income reported, the more valid the report. ${ }^{12}$ Here they have several supporting arguments. The income respondent may forget minor sources of income - money a hobby brought in or that his child made selling news-

\footnotetext{
"One could compare the SCF and CQC income reports with reports of total income obtained by the Internal Revenue Service (IRS) on tax returns and compare the wage and salary reports of less than $\$ 3,000$ with data collected by the Bureau of Old-Age and Survivor's Insurance (OASI). But there are questions on the conceptual comparability and completeness of these reports. In view of these factors and the difficulty of analyzing three-way comparisons, a detailed analysis of this sort was not undertaken in this study. Comparisons of census data with IRS and OASI data are given elsewhere in this volume.

${ }^{12}$ Some evidence is available. Three-way comparisons of SCF, CQC, and IRS data show that in the $\$ 3,000-7,499$ total income class, CQC total income reports correspond more closely to the IRS one than do the SCF reports; for incomes above $\$ 7,500$, the scF reports correspond more closely.
} 
papers. Or he may understate his income because he thinks the survey organization will report the amount to the Internal Revenue Service. To the extent that a report shows higher income because either kind of understatement was avoided, it will be better. A different sort of argument is that since survey aggregates fail to come up to an adjusted personal income total, such as the one calculated by the Department of Commerce, any report that gives a higher income will be better because it will lessen the gap. But this argument applies to the validity of totals not of individual reports, which are our concern here.

On the other hand, a respondent may overstate his income because he forgets to subtract all business. or farm expenses from entrepreneurial incomes or because he includes income of another period in "last year's income." Or the concept of the entrepreneurial income to be measured may differ from one survey to another; one survey wanting such income reported on a cash basis, the other on an accrual basis; one including, the other excluding, reinvested profits. If a report shows higher income for any of these reasons, it is less valid. In general, however, people accept as more valid the report with the higher income. Again, this is an assumption, not a tested conclusion.

\section{LESSONS FROM THE RESULTS}

\section{The Similarity of the Income Reports}

We have stressed the differences in the various results obtained by the two surveys. Indeed this was necessary since through analysis of the differences we can infer their cause. Yet in some respects the SCF and CQC results are remarkably parallel.

Under optimal coverage (the same unit, adults, income recipients, and first-quality respondents) 63 per cent of the units reported income in the same income class to both surveys, 93 per cent in either the same or an adjacent class. With less satisfactory coverage (the same unit but other conditions not controlled) the corresponding percentages were 57 and 89 . Even the SCF and CQC income distributions based on all units covered by both surveys (including the 17 to 22 per cent of the units in each survey that were not covered in the other survey) correspond closely. And both these last distributions purport to represent the entire population. The medians are separated by only $\$ 115$ and the largest difference in the cumulative percentage distributions is 2.3 percentage points. (Table 2 shows the distributions at the three stages.)

The reason for the similarity is that major sources of differences offset one another. First, the income of unmatched units was low on 
the average in both surveys. Since there were more unmatched units in the $\mathrm{CQC}$ than in the SCF, this factor has the effect of lowering the $\mathrm{CQC}$ income distribution relative to the SCF one. Another factor producing the same effect was the SCF's more complete coverage of sources of income and higher reported income for completely matched units. On the other hand, the CQC identified more income receivers and more adults and interviewed more first-quality respondents, factors which by and large have the opposite effect; they tend to raise the level of income in the CQC distribution.

The income analyst should be aware of the way one class of error may sometimes counterbalance another, as in this case. He should also be alert to the possibility that this may not always be true in survey comparisons.

\section{Coverage of Units}

As noted earlier, the SCF missed more units than the CQC did, and these missed units were concentrated in nonmetropolitan cities of 50,000 or more and in the open country. As a result of this finding, several new sampling procedures have been instituted in recent SCF samplings.

The most notable of these is the use of city directories as a source of sample addresses in medium-sized cities. Sample blocks are selected. Interviewers are then sent to each block to see what dwelling units the city directory enumerators may have missed. Finally separate selections of addresses are made from both those initially listed by the city directory and the additional addresses picked up by the SCF interviewers. The theory underlying this procedure is that any single enumerator will miss some dwelling units, perhaps 5 per cent. Different enumerators, however, will miss different dwelling units. To the extent that they do in fact miss different ones, the double listing reduces net misses.

A second innovation is the use, for small towns and open-country areas, of segments whose size is made smaller than before and carefully controlled. According to SCF procedures, interviews are to be taken from all units within a segment. Decreasing its size to an area containing five to seven dwelling units should make possible a more intensive scrutiny of the area for dwelling units, and thus fewer will be missed.

Between 1955 and 1956, presumably as a result of these changes, the relative coverage of the population by the SCF increased by 6 per cent. In 1955 the SCF sample (inflated) accounted for 89.5 per cent of the Current Population Survey's estimate of occupied dwelling units. In 1956 the comparable figure was 95.3 per cent. The 
reduction of missed units appears to have had the effect of shifting the income distribution downward from what it otherwise would have been.

\section{Noninterviews and Partial Interviews}

Before looking for applications of the findings of the present study, we will consider the frequency and treatment of noninterviews and partial interviews in the regular Current Population Surveys (CPS) and the annual sCFs. But first, we should point out that the CQC and the CPS differ greatly from each other. The CQC was a special survey in which selected enumerators and an extremely detailed demographic and income questionnaire were used. The CPS uses similar enumerative techniques but a relatively simple questionnaire containing four questions about income. Thus some of the generalizations from the SCF-CQC study cannot be properly applied to the interpretation of the CPS. This is not true of the SCF since data for one-half of the sample of the regular 1950 SCF were analyzed in this study.

In the 1954 CPS and SCF, noninterviews constituted 5 per cent (CPS) and 12 per cent (SCF) of the respective samples; partial interviews, 10 per cent (CPS) and 2 per cent (SCF). Both surveys take account of noninterviews by increasing the weights of sampling strata in which the noninterview rate is highest; decreasing the weights of those in which it is lowest. In the SCF this system of weighting leaves the income distribution almost unaltered though it has important consequences for the distribution of other variables (for example, car ownership). Presumably the effect of the weighting in the CPS is similar.

On the other hand, the CPS excludes partially interviewed units from the tabulations and makes no adjustment for them, on the implicit assumption that partially and completely interviewed units have the same mean income, the same income distribution. In the SCF, where this problem is small, partially interviewed units are assigned the mean income of units defined as "similar" on the basis of occupation, type of spending unit, place of residence, and holdings of liquid assets. The mean income assigned to these partially interviewed units is higher than the mean for those completely interviewed; consequently the income distribution of all the units is raised slightly.

In the SCF-CQC study the incomes of about 69 per cent of the units not interviewed in the SCF were reported to the CQC. If this 69 per cent are similar to units for which there is no report in either survey, then the entire group had a somewhat higher average in- 


\section{S C F A N D C Q C}

come (by about $\$ 200$ ) than the units whose interviews were completed. This implies that the SCF procedure for the units not interviewed results in some understatement of income.

The ratio of units not interviewed to those partially interviewed in the CQC ( 1 to 5 ) is so different from the corresponding ratio in the CPS (1 to 2) that it is doubtful whether the information obtained here can be properly applied to the CPS.

\section{Coverage within the Family}

The finding that the 1950 SCF was less successful than the CQC in identifying income recipients has already led to improvements in SCF techniques. An analysis showed that to obtain income reports from supplementary income recipients the interviewer had to ask a long series of somewhat ambiguous questions which generally yielded negative answers and which appeared unnecessary to the respondent. The questionnaire was revised to make the interviewer's task easier. Detailed questions on sources of income are now asked of the head of the unit. Supplemental questions follow: "Did your wife have any income during the year? Did your son (or other person) have any income?" "Yes" answers to these lead questions are followed by two other questions: "How much did she (he) receive? Was it from wages, salary, a business, or what?" In this way the psychological hazard of asking many "unnecessary" questions of other possible income recipients is eliminated. This new approach -adopted first in the 1954 sCF-worked. The accompanying tabulation shows that the proportion of units with multiple income receivers increased sharply.

PERCENTAGE OF DISTRIBUTION OF SPENDING UNITS

$\begin{array}{lccc}\text { NUMBER of } & \begin{array}{c}\text { New Approach } \\ 1954 \text { SCF }\end{array} & \begin{array}{c}\text { Old Approach } \\ 1953 \text { sCF }\end{array} & \begin{array}{c}1954-1953 \\ \text { Difference }\end{array} \\ \text { INCOME RECIPIENTS } & 100.0 & 100.0 & \\ \text { Total } & 0.8 & 0.5 & +0.3 \\ \text { Zero } & 68.3 & 74.3 & -6.0 \\ \text { One } & 27.9 & 23.3 & +4.6 \\ \text { Two } & 2.5 & 1.8 & +0.7 \\ \text { Three } & 0.5 & 0.1 & +0.4\end{array}$

This particular problem is not relevant to the CQC or the CPS where standard instructions call for interviews with each person rather than only with the head of the unit.

\section{First-Quality Respondents}

Both the CQC and the SCF instructed interviewers to deal with first-quality respondents, but the $\mathrm{CQC}$ found more of them. And apparently the quality of the respondent does matter. Though 
units generally reported income in a higher income class to the SCF, the net surplus was highest when the SCF interviewed a first-quality respondent and the CQC did not; lowest when the $\mathrm{CQC}$ interviewed a first-quality respondent and the SCF did not. This finding that income reports of first-quality respondents tend to be higher than those of second-quality ones, ceteris paribus, is reasonable, as a first-quality respondent is selected as the person most likely to be familiar with the income or other financial transactions of the spending unit.

\section{Number of Questions and Size of Income Reported}

One operating maxim of the survey technician which found support in this study is the proposition that the total income reported will increase as the number of questions asked about different sources of income increases. The CQC asked six questions about transfer payments, the SCF only two. Unlike the results for other components about which the SCF asked more questions, reports of this type of income were made more frequently to the $\mathrm{CQC}$ than to the SCF, and the reported amounts were larger. Consequently, in interpreting the results of annual income surveys, the income analyst should expect the survey with the most questions to have the highest reported incomes.

\section{Reporting of Wages and Salaries}

The CQC and the SCF employed widely differing techniques to obtain reports of wage and salary income. Taking the job history approach, the CQC asked questions about each place and period of employment and then up to seven questions about the income received from each employer. On the other hand the SCF asked only three general questions about wages and salaries. Yet more respondents reported the receipt of wage and salary income to the SCF, and, if they reported it to both surveys, they reported larger amounts to the SCF.

These results indicate that survey technicians should usually prefer the simpler SCF approach to a job history one, since the former requires fewer questions and less time and apparently yields as good or better results. Perhaps the $\mathrm{CQC}$ questions suggested regular, well-ordered jobs and the incomes related to such jobs. If so, the $\mathrm{CQC}$ may have tended to miss income from irregular or part-time employment, such as income from mowing lawns or from consultations.

\section{Farm Income}

As noted earlier, analysis of the reports of farm income did not establish the superiority of either the short CQC schedule (three ques- 
tions) or the detailed SCF farm schedule (nineteen questions). Consequently in the 1954 SCF a separate farm schedule was abandoned, and a simple five-question sequence-similar to the CQC one but with a more explicit control of capital expenses-was adopted as a substitute.

\section{CONCLUSIONS}

At a more general level than the previous discussion, the study has demonstrated once again that differences in survey techniques affect the resulting income distributions of surveys, whether they are conducted by different organizations or by the same organization at different times. Indeed the income analyst should be particularly alert to the effect of changes in procedures in a regularly conducted survey. Whenever possible he should restrict himself to the use of data drawn from only one survey or from surveys that employ similar techniques. And those conducting surveys have a responsibility to inform the public of changes in techniques and of their likely effect on the income distributions they publish.

As to the present study, if a similar one were to be undertaken, interviews should be conducted during approximately the same period in the two surveys. This would remove memory error as a possible explanation of differences between their reports. Also it would be desirable to obtain the names of respondents in both to facilitate matching. Otherwise, as in the present study, the interpretation of the results is obscured. Would the placement of the unmatched units in their proper groups have changed the results obtained? We do not know; we can only bring the problem to the attention of the user of this study.

Finally, research in methods should be executed more rapidly than the present study was. Had our results been available sooner, improvements in survey techniques might have been undertaken sooner, and their benefits passed on to the ultimate consumer of the data.

\section{Appendix A: The Matching Procedure}

Since names were not obtained in the $1950 \mathrm{SCF}$, it was necessary to institute a matching procedure by which families and unrelated individuals interviewed in both SCF and CQC could be designated as identical or nonidentical units.

A review group of four professional persons examined interviews taken at the same address by the SCF and CQC. By comparing the demographic characteristics of the unit as reported to each survey, and other information in the respective interviews, the review group was able to arrive at an agreement on whether the units were "positive matches" 


\section{MATCHING AND Q UALITY STUDIES}

(99 per cent probability that the units were identical), "probable matches" ( 95 to 99 per cent probability), or "nonmatches" (less than 95 per cent probability). The "matched units" group mentioned in the body of the paper consists of both positive and probable matches.

The demographic characteristics considered in assigning the match status included sex, age, occupation, education, veteran status, length of marriage, home-owning status, number of adults and children, and number of children born in 1949 or 1950 . All of the individual characteristics refer to the head of the spending unit.

Special weight in assigning match status was given to agreement on unusual characteristics as, for example, when both surveys reported the head as sixty-five years or more ("very old").

\section{Appendix B: Income Questions Asked in the Survey of Consumer Finances}

In the 1950 SCF the following questions were asked of spending units whose heads were primarily engaged in an occupation other than farming. (The Post-Enumeration Survey questionnaire, used in the CQC, is shown on page 237 of this volume.) Interviewers were instructed, where possible, to obtain answers from the head of the spending unit.

(In this survey, all over the country we are trying to get an accurate picture of people's financial situation. One thing we need to know is the income of all the people we interview. We start with wages and salaries, yours and those of your. . . . SU)

\section{Head Wife and of $S U$ others}

1. How much did you $(\mathrm{R} \& \mathrm{SU})^{1}$ receive from wages and salaries in 1949? I mean, before they deducted anything such as taxes, social security, and so on?

If income

from wages and salaries
2. Does that include bonuses, overtime and commissions? (If no) How much was that?

3. Did you ( $R \& S U$ ) have any pay from work outside your regular work? (If yes) How much?

4. Did you ( $R \& S U$ ) receive income from roomers and boarders? (If yes) How much?

5. Did you ( $R \& S U)$ receive any money from other rent? (If yes) How much was it after allowing for your expenses?

${ }^{1} \mathbf{R}=$ respondent; $S U=$ spending unit. 


\section{S C F A N D C Q C}

6. Did you ( $R \& S U)$ receive any money from interest, dividends, a trust fund, or royalties? (If yes) How much was that? If $(\mathrm{R} \& \mathrm{SU}) \quad 7$. What was the profit, or owns or partly loss, of your business in owns an unin- 1949? I mean, your share, corporated business

(P. 2, Q. 16) if you have partners, and after deducting expenses?

[Profit]

[Loss]

8. How much did you take out from your business in 1949 , including any salary you paid to yourself or other withdrawals?

$\$ \ldots . . .$.

9. Is that included in the profit you gave me before? [Yes]

[No]

10. Did you ( $R \& S U$ ) have any income from professional practice or other selfemployment or farming (other than what you have already mentioned)? (If yes) What was your net income for the year from your profession (self-employment, farming) considering all the money you took in and deducting your expenses?

11. Did you ( $R \& S U$ ) receive veterans' pension, veterans' school allotment, family allotment, or veterans' bonus from a state? (If yes) How much did that amount to?

12. How about retirement pay, unemployment compensation, old-age pensions, annuities, alimony, regular contributions, or welfare? Did you (R \& SU) receive any income of this sort? (If yes) How much?

Just to be sure I didn't get anything wrong, I'll add this up

\section{Is that about right?}

SCF heads of spending units whose primary occupation was farming were asked the following set of questions: 
(Now, we would like to know about your farm expenses)

1. Did you buy any livestock during the year? (If yes) How much did that come to?

2. Did you pay out any wages to farm hands? (If yes) How much was that?

$\$$

3. About how much did you pay for insurance on your crops and stock and buildings?

4. How much did you spend for feed in 1949 ?

5. How much did you spend for seed?

6. What did you spend for lime and fertilizer during the year?

7. How much of what you spent for fuel, tires, and repairs to your car was for farm business?

How much did you spend for fuel, tires, and repairs for your tractor, your truck, and any other farm machinery?

9. Are you paying anything on a mortgage or other farm loans? (If yes) What did the interest on these loans come to in 1949 ?

10. Did you pay any cash rent for this farm or for other farm land? (If yes) How much was that?

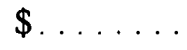

\section{$\$ \ldots \ldots$}

$\$ \ldots \ldots$

11. Did you have any custom work done by others last year such as combining, plowing, or baling? (If yes) How much did you pay for it?

12. Did you have any other expenses? For instance, for storing crops, renting machinery, containers, irrigation, ginning, etc? (If yes) How much did they come to?

13. Now adding all of these figures together, I find that your farm expenses in 1949 were.

(Let's consider now what money you took in last year before deducting any of these expenses.)

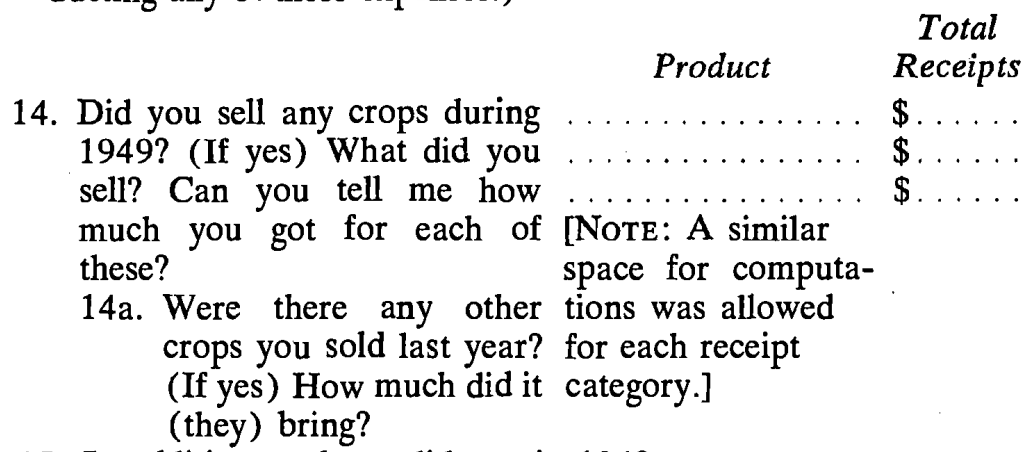

15. In addition to these, did you in 1949 put any crops under Commodity Credit Loan? (If yes) How much did you get on the loan? 
16. Did you sell any livestock in 1949 ? (If yes) What did you sell? How much did you get for them?

16a. Was there any other livestock you sold during 1949? (If yes) How much did they bring?

17. Did you sell any butter, milk, cream, poultry or eggs last year? (If yes) What was that? How much did you get for them?

17a. Was there anything else of this sort that you sold in 1949? (If yes) How much did you get for them?

18. Did you sell any fruits and vegetables during 1949 ? (If yes) What did you sell? How much did you get for them?

18a. Were there any other fruits and/or vegetables that you sold last year? (If yes) How much did you get for them?

$\$ \ldots . .$.
$\$ \ldots$

19. Did you sell anything else off the farm last year? (If yes) What else did you sell? What did these bring altogether last year?

20. Did you receive any Government Payments during the year, such as soil conservation payments? (If yes) How much did you receive?

21. That means you got altogether from your farm last year .....

\section{$\$$}

$\$ \ldots$.

21a. Now deducting your expenses ( $Q .13$ bottom of previous page) we find that your net income from farming was about.

\section{$\$$}

Does that seem about right?

(Enter here the net farm income from bottom of previous page)

\section{ASK EVERYONE}

\section{Head of Wife and $S U$ Others}

22. Did you (other members of SU) do any custom work last year? (If yes) How much did you get for it? $\$ \ldots \ldots$

23. Did you (other members of SU) earn any wages or salary during 1949? (If yes) How much was that?

\section{$\$$}

$\$ \ldots \ldots$

24. Do you have any land or other property that you are renting out? Do you have any investments (mortgages) that you get interest or dividends on? (If yes) How much did you receive during the year in interest, dividends, rent?

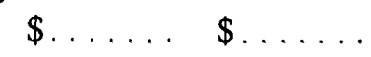


M A T C H I N G A N D Q U ALIT Y S T U D I E S

(If owns an unincor- 25. What was your net porated business $P$. income from your 2, Q. 16) business?

26. Did you (or other members of the SU) receive veterans' pension, veterans' school allotment, family allotment or veterans' bonus from a state? (If yes) How much was that?.

$\$ \ldots \ldots \ldots$

27. Did you (or other members of SU) have any income from any other source, such as roomers, retirement pay, old age pensions, and so on? (If yes) How much was that?.........

28. Adding these to your net income, we find your total income in 1949 was about

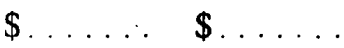

